SALUD PUBLICA

Pev. Chil. Pediatr. 56 (4) $263-270,1985$

\title{
Desarrollo Psicosocial de Adolescentes de 12 A 15 años
}

\author{
Dr. Carlos Almonte V. ${ }^{1}$ : Psic. Gabriela Sepúlveda R. ${ }^{2}$; Dr. Alfredo Avendaño B. 3 ; \\ De Carlos Valcnzuela Y.4.
}

Psychosocial development in Early adolescence

\begin{abstract}
This study describes somc features of psychosocjal development, in 383 adolescents, 12.6 to 15 years old, sclected for a follow-up siudy on growth and development extending from 5 to 20 years of age. Some aspects of personal development and interpersonal relationships in family, school and social seting are analjzed. The behavioral aspects werc teported in a previous publication. Sone risk factors for mental bealth, allowing distinctions between normal adolescents, normal adolescents at risk, and adolescents with neuropsychiatric pathology were identifyed. Risk factor derived from personal development include negative self concepts, negative world visions, unsitistactory cmotional cxpression, and socially maladjusted behaviors like excessive alcohol consumption. drug abuse and robbery. The most relevint covironmental risk factor is probably represented by unsatisfactory interpersonal relationships, specially within the family setting.
\end{abstract}

(Key words: Adolescenec. Bchavior. Developement. Psychiatric disorders. Psychosocial devefopement. Risk tactors?.

El desarrollo neuropsiquico normal y patológico está condicionado por el intetjuego permanente de factores genético-disposicionales y ambientales. siendo los más importantes de estos últimos, la influencia de la familia y de las instituciones educacionales ${ }^{2}$. En la medida en que estos factores interactuan de un modo favorable es más probable que el adolescente llegue a ser un adulto sano, tanto en su estruclura personal como en su adaptación social. Cuando las interacciones son desfavorables se frena o distorsiona el desarrollo personal y pueden aparecer conductas que revelan dificultad en la adaptación social, tales como alcoholismo, abuso de drogas, agresividad y delincuencia. Li mayor vulnerabilidad del adolescente, que se manifiesta por la alta frecuencia de trastornos mentales y psico-sociales en este grupo $^{3}-4-5$, nos ha motivado a investigar la relación entre el desarrollo psicoso-

1. Médico Psiquiatra. CIDLN, Servicio de Neurologia y Neutocirogía, Hospital Clínico de lá Universidad de Chile.

2. Psicólogo. CIDIN, Servicio de Neurología y Neurocirugía. Hospital Clínjco de la Universidad de Chile.

3. Médico. Depto. de Pediatría. División Norte. Facultad de Medicina. Universidad de Chile.

4. Médico. Depto. de Biología Celular y Genética. Facultad de Medicina. Universidad de Chile.

Trabajo financiado por Subvención M 7978445, Unjversidad de Chile, Dirección General Acudémica. Departamento de Desarrollo de la Investigación. cial en las areas personal, familiar, educucional y social y algunas conductas desadaptivas, como las ya mencionadas, con el fín de identificar factores de riesgo para la salud mental, y poder asi proponer medidas preventivas en los jóvenes calificados de más alto riesgo, y medidas terapéuticas en jovenes con patologia manifiesta.

En este trabajo se analizan algunos aspectos do desariollo psicosocial de un grupo de adolescentes en las etapas de pre-pubertad y pubertad. comprendiendo tantos los aspectos individuales como interpersonales on relación al medio familiar, educacional y social. En un trabajo anterior se describicron algunas características conductudles de este grupo ${ }^{1}$.

\section{SUJETOS Y METODO}

La muestra estuvo constituída por 383 adolescentes de ambos sexos, cuyas edades fluctuaron entre 12,6 y 15 años (190 hombres y 193 mujeres). El grupo forma parte de la muestra de un estudio longitudinal del crecimiento y desarrollo que se realiza en $10 \%$ de los niños que ingresaron a la enseñanza básica fiscal del área hospitalaria Norte de Santiago el año $1973^{6}$.

Los antecedentes fueron recogidos mediante el cuestionario de Aspectos Psicosociales del Adolescente, de G. Sepúlveda y C. Almonte, descrito en un trabajo anterior, que evalúa las 
areas personal-vocacional, familiar, escolar y social $1^{1}$. Li] procesamiento fue realizado en el Departamento de Informática, del Hospital Clínico de la L niversidad de Chile. Las comparaciones posibles sun numerusas, por to que sólo se realizaron las pruebas de significación estadística en aqueIJos casos, en que segun nuestro criterio técnico, lá compiración de variables era relevante. Se realizó la prueba de Jl cuadrado con los respectivos gratos de lihertad, la prueba de $Z$ para proporciones y la distribución de Poisson. C'n hecho, se consideró significativo solo cuando la probibilidad de azar fue inferior a 0.05 .

Investigamos las imáenes o conceptos que el joven tiene de sí mismo y de las otras personas en las ireas familiar, escolar y social. Desde un punto de vista operacional consideramos que las imágenes exan positivas, cuando los jóvenes se describían asi mismo o a otros, como personas cálidas afectuosas, comprensivas, solidarias y equilibradas. La imagen negativa corresponde a las de las personas que se consideran asi mismas o a otras como rigidas, exigentes, poco comprensivas, rechazantes, pasivas o irresponsables.

En el área personal, buscamos ademís la autoimagen: una imagen personal positiva refleja confianza en si mismo, lo que facilita la autonomia personal, en cuanto a toma de decisiones $y$ enfrentamiento de problemas. Una imagen negativa de sí mismo refleja Calta de confianza en sí, y en las propias apacidades, lo que dificulta $\mathrm{cl}$ logro de la autonomía personal y el establecimiento de relaciones satisfactorias. Estas imágenes positivas o negativas pueden ser aceptadas o no por la persona; así consideramos egosintóni$\cos$ a los jóvenes que aceptan su imagen como propia y correspondiente y simpatizan con ellas y egodistónicos cuando la imagen propia no se acepta. En los casos en que hay anbigüedad frente a la aceptación de la imagen propia. hablamos de egosinton id-egodistonía.

De las imágenes que se obtienen podemos inferir la visión del mundo o cosmovisión (percepción de si y de otros), que refleji en gran medida la salud psíquica y la adaptación al medio.

Para estos propósitos definimos diferentes tipos de visiones:

La visión idealista implica percibirse asi mismo y a los demás como personas positivas. trascendiendo las realidades inmediatas o concretas de las acciones, al considerar a las personas en términos de potencialidades y valores. Esta visión favorece relaciones interpersonales satisfactorios en un contexto de respeto y confianza mutua.

La visión realista comprende percepciones objetivas de si y de los otros, considerando tanto los aspectos positivos como negativos, esta visión deriva en actitudes pragmáticas en la relación con el mundo, los individuos que poseen esta visión privilegian las realidades concretas y corren el riesgo de no considerar valores superiores o trascendentes.

Las visiones negativas se dan en personas que tienen una imagen negativa de sí misma, de los demás, o ambos, con visiones distorsionadas o parciales de la reatidad, resultantes de enfocar la atención sólo en algunos aspectos concretos, no logrando la configuración global, lo que puede conducir a adaptaciones insatisfactorias.

Investigamos las relaciones interpersonales, en las áreas familiar, escolar y social. Definimos para el propósito de este trabajo las relaciones inter. personales como satisfactorias, cuando están cla. ramente diferenciados los roles, y definidas las normas; estimulan la autonomía de los sujetos en interacción $y$ dan protección y seguridad. Estas relaciones se dan cuando los individuos ejercen un rol claro, definido y flexible, estableciendo limites generales definidos que estimula el desarrollo personal satisfactorio. Hablamos de relaciones instaisfactorias, cuando los roles $y$ normas no están claramente definidos; o hay excesiva rigidez, laxitud o inestabilidad en el ejercicio de éstos, dificultando el proceso de autonomia y favoreciendo frustraciones o conflictos prolongados. Estas relaciones ocurren cuando los individuos ejercen su rol en forma autoritaria o excesivamente permisiva, fomentando conductas de rebeldía o sumisión exagerada del otro, dificultando el desarrollo de la responsabilidad individual.

La expresión emocional es otro aspecto personal que investigamos. Desde un punto de vista operacional, consideramos que una emoción se expresa satisfactoriamente cuando corresponde en calidad, intensidad y duración a la situación que la originó y cuando se comunica en un contexto ambiental de confianza y aceptación, postergando su expresión cuando es necesario para la aceptación social. La expresión emocional es insatisfactoria cuando es muy intensa, prolongada o inadecuada a la situación que la produjo, o no se expresa. Consideramos la expresión de una emoción como parcialmente satisfactoria, cuando coxisten expresiones adecuadas con otras insatisfactorias.

En el área social investigamos la participación de los jôvenes en actividades de tipo recreativo y cultural, realizadas en grupos, ya sea de familiares o pares. Definimos como actividad social satisfactoria, aquella que es frecuente, variada y se da en distintos contextos; insatisfactoria cuando la actividad social es escasa, poco variada, no estimulante, ni enriquecedora. La calidad de la actividad 
Tabla I.

Expresión de Emociones

$(\mathrm{N}$ Total $\mathbf{3} \mathbf{3 8 3}$ )

\begin{tabular}{|c|c|c|c|c|c|c|c|c|}
\hline \multirow{2}{*}{$\begin{array}{l}\text { Expresión } \\
\text { Emociones }\end{array}$} & \multicolumn{2}{|c|}{ Satisfactoria } & \multicolumn{2}{|c|}{$\begin{array}{l}\text { Parcialmente } \\
\text { Satisfactoria }\end{array}$} & \multicolumn{2}{|c|}{ Insatisfactoria } & \multicolumn{2}{|c|}{ No contestan } \\
\hline & $\mathbf{N}$ & $\%$ & & $\%$ & $\mathbf{N}$ & $\%$ & $\mathbf{N}$ & $\%$ \\
\hline $\begin{array}{l}\text { Rabia } \\
\text { Temor } \\
\text { *Tristeza } \\
\text { Alegría } \\
\text { Afecto }\end{array}$ & $\begin{array}{r}10 \\
76 \\
83 \\
334 \\
165\end{array}$ & $\begin{array}{r}2.6 \\
19.8 \\
21.6 \\
87.2 \\
43.1\end{array}$ & $\begin{array}{l}19 \\
84 \\
69 \\
18 \\
78\end{array}$ & $\begin{array}{c}4.9 \\
21.9 \\
18 \\
4.7 \\
20.3\end{array}$ & $\begin{array}{r}336 \\
213 \\
211 \\
22 \\
124\end{array}$ & $\begin{array}{r}87.7 \\
55.6 \\
55.1 \\
5.7 \\
32.4\end{array}$ & $\begin{array}{r}18 \\
10 \\
20 \\
9 \\
16\end{array}$ & $\begin{array}{l}4.8 \\
2.7 \\
5.3 \\
2.4 \\
4.2\end{array}$ \\
\hline
\end{tabular}

* Diferencia significativa gor sexo: el hombre expresa más insatisfactoriamente la tristeza que la mujer. $N=$ nimero de casos.

social es un indicador de la integración social.

Los aspectos descritos se relacionaron con conductas que interfieren en la adaptación social, tales como alcoholismo, abuso de drogas y delincuencia, las que fueron motivo de una publicación anterior.

\section{RESULTADOS}

\section{Area Personal}

La mayoría de los sujetos, $82,3 \%$, tiene una imagen personal positiva; sólo $13 \%$ tiene imágenes negativas de sí mismo. En $65,5 \%$ encontramos egosintonía y en $6 \%$ egodistonía. Los casos con ambigüedad en la aceptación de su imagen fueron $24,8 \%$.

Al correlacionar la imagen personal con conductas socialmente desajustadas, encontramos que los jóvenes que tenían imágenes negativas de sí mismo tendian a presentar con mayor frecuencia embriaguez, consumo de drogas y hurtos.

En relación con la expresión emocional, las emociones negativas, rabias, temor y tristeza, son expresadas en forma insatisfactoria por la mayoría de los jóvenes estudiados, siendo la más insatisfactoria la rabia, $87.7 \%$ (Tabla 1). En cambio, las emociones positivas como alegría y afecto son expresadas más frecuentemente en forma satisfactoria (alegría $87,2 \%$, afecto $43,1 \%$ ). En cuanto al afecto cabe destacar que $32,4 \%$ lo expresa en forma insatisfactoria. La única diferencia significativa por sexo se encontró en la expresión de tristeza, ya que el hombre tiende a expresarla de manera más insatisfactoria que la mujer.

Al relacionar la expresión emocional con conductas socialmente desajustadas, encontramos que todos Jos jóvenes de nuestro grupo que hurtan tienen una expresión emocional insatisfactoria de rabia, temor $y$ afecto.

\section{Area Familiar}

La imagen de familia, en la mayoría de los casos, $89,8 \%$, es positiva y en $6,3 \%$ negativa.

Los jóvenes con imagen positiva de la familia no presentan conductas socialmente desajustadas; en cambio los que tienen imágenes negativas tienden a presentar con mayor frecuencia embriaguez, uso de drogas y hurtos.

La imagen del matrimonio fue positiva en $79.9 \%$ de los casos y negativa en un $13,4 \%$, encontrándose una diferencia significativa por sexo, ya que un porcentaje mayor de hombres presenta una imagen positiva y un mayor porcentaje de mujeres tiene imágenes negativas. Es interesante destacar que los jóvenes que tienen imágenes negativas del matrimonio también tienen imágenes negativas de las relaciones conyugales de sus padres, ya sea porque éstas son conflictivas o inexistentes.

En nuestra muestra predominan imágenes positivas de todos los familiares, sin diferencias significativas por sexo (Tabla 2). La imagen de padre es positiva en la mayoría de los casos $(79,4 \%)$, y negativa en un porcentaje bajo (11\%). La imagen de madre es positiva en una mayor proporción de casos $(94,6 \%)$ que la imagen de padre. La imagen de hermanos, si bien, en la mayoría de los jôvenes de la muestra es positiva $(64,2 \%)$ es la que tiene mayor proporción de imágenes negativas $(26,6 \%)$

Tabła 2 .

Imágenes del Area Familiar

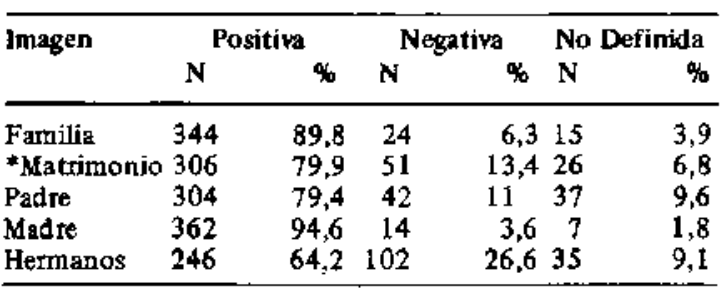

* Diferencia significativa por sexo. 
Tabla 3.

Relaciones Familiares*

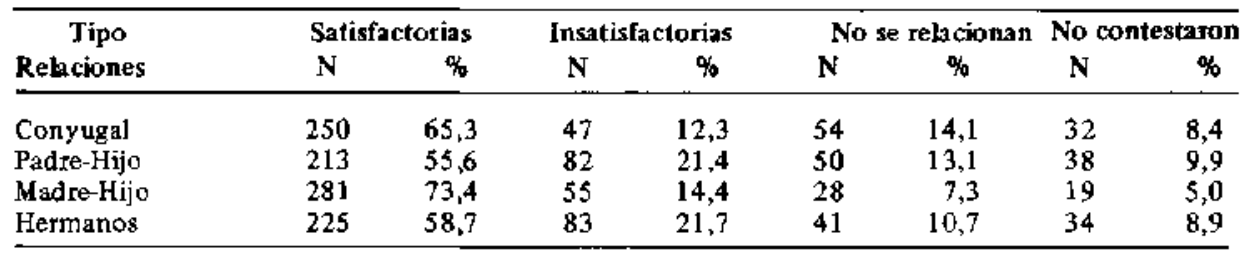

* No hay diferencias significativas por sexo.

La imagen del padre se relaciona significativamente con la imagen de las relaciones conyugales, es decir, cuando una de ellas es positiva o negativa, la otra también lo es, relación que no se encuentra con la imagen de madre.

La inagen de los padres tiende a relacionarse con la imagen personal, de modo que a imágenes personales positivas corresponden más frecuentemente imágenes de padre y madre positivas; y a las imágenes personales negativas, imágenes parentales negativas.

En cuanto a relaciones interpersonales familiares, la mayoría de los sujetos mantiene relaciones satisfactorias (Tabla 3). Las relaciones conyugales entre los padres son calificadas como satisfactorias por $65,3 \%$ de los jóvenes e insatisfactorias en $12,3 \%$. Los padres no mantenían relaciones en $14,1 \%$. La relación con la madre aparece como la más frecuentemente satisfactoria $(73,4 \%)$ y la que tiene la menor proporción de no relación. La relación con el padre es vista como satisfactoria por $55,6 \%$ del grupo, y por un porcentaje importante como insatisfactoria o sin relación $(34,5 \%$ en conjunto). Las relaciones con los hermanos son satisfactorias en el $58.7 \%$ de los casos, e insatisfactorias en el $21,7 \%$, no dándose la relación en el $10,7 \%$.

Al correlacionar la imagen que el joven tiene de sus familiares con el tipo de relaciones que establece con ellos, encontramos una relación estadisticamente significativa con la imagen de padre $y$ hermanos: cuando la imagen es positiva, las relaciones son insatisfactorias o no hay relación. En cambio la imagen de la madre varia menos con el tipo de relación; es decir, a pesar de relaciones insatisfactorias, la madre sigue siendo percibida generalmente en forma positiva.

\section{Area Escolar}

En nuestro grupo, la imagen del colegio es positiva en la mayoría de los jóvenes $88,7 \%$ y negativa sólo en el $8,4 \%$; no existiendo diferencias significativas por sexo. (Tabla 4).

La actitud hacia el colegio tiende a correlacionarse significativamente con el rendimiento y la conducta; es decir, cuando la actitud hacia el colegio es positiva, el rendimiento y la conducta son satisfactorias y si éstos últimos son inadecuados, la imagen del colegio tiende a ser negativa. La imagen de los companteros es en la mayoría positiva $(62,4 \%)$, si bien un $31 \%$ tiene imagenes negativas. La imagen de los profesores es en la mayoria positiva $84,1 \%$ y negativa en el $11 \%$. En cuanto a la imagen de si mismo como estudiante, vemos que un alto porcentaje, $81 \%$, tiene imágenes positivas y el $12,6 \%$ negativas, encontrándose una diferencia estadisticamente significativa por sexo, ya que las mujeres tienen una mayor proporción de imágenes positivas en relación a los hombres.

En cuanto a relaciones interpersonales, predominan relaciones de tipo satisfactorio, tanto con

Tabla 4.

Imágenes Area Escolar

\begin{tabular}{lcrrrrrr}
\hline lmagenes & \multicolumn{2}{c}{ Positiva } & \multicolumn{2}{c}{ Negativa } & \multicolumn{2}{c}{ No definido } \\
& $N$ & $\%$ & N & $\%$ & N & \\
\hline Colegio & 340 & 88,7 & 32 & 8,4 & 11 & 2,9 \\
Compañeros & 239 & 62,4 & 119 & 31,1 & 25 & 6,6 \\
Profesores & 322 & 84,1 & 42 & 11 & 19 & 4,4 \\
*Imagen de si & & & & & & \\
como estudiante & 310 & 81 & 48 & 12,6 & 25 & 6,7 \\
\hline
\end{tabular}

- Diferencia significativa por sexo. 
profesotes como con compañeros, sin embargo un porcentaje importante de jóvenes tiene relaciones insatisfactorias o no se relacionan con companteros y profesores.

Se dio una asociación estadísticamente significativa entre el tipo de relaciones y la imagen que se tiene de profesores y compañeros; es decir, cuando hay una imagen positiva Ja relación es satisfactoria y a medida que se deteriora la imagen aumentan las relaciones interpersonales insatisfactorias coincidiendo la imagen negativa con la no relación tanto en hombres como en mujeres.

En cuanto a relaciones interpersonales con compañeros, éstas son satisfactorias en $67,4 \%$, insatisfactorias en $23,5 \%$ y no se relacionan en $3,9 \%$. Con los profesores las relaciones fueron satisfactorias en $59,8 \%$, insatisfactorias en $25,8 \%$, no se relacionan en $5,5 \%$. Los porcentajes que faltan para lograr el $100 \%$ se deben a falta de respuestas.

\section{Area Social}

En nuestro grupo de jóvenes la imagen de otras personas en general es positiva en la mayoria $(77,5 \%)$ y negativa de un porcentaje menor $(14,3 \%)$, no precisable en el $8,2 \%$ sin mostrar diferencias significativas por sexo. La imagen respecto a personas del mismo sexo es también positiva en la mayoría, $80,9 \%$ y negativa en sólo el $12,2 \%$, en igual proporción en hombres y mujeres. Frente a la imagen de personas del sexo opuesto, se encontró una diferencia estadísticamente significativa por sexo, ya que en el hombre hay un mayor porcentaje de irnágenes positivas, las que se dan en el $85,7 \%$ de los jóvenes, dándose la negativa en sólo 7,3\%. En cambio, en la mujer la visión positiva del sexo opuesto se da en el $68,8 \%$ de los casos, y la negativa en el $22,7 \%$. El hecho que la suma de porcentajes no sea $100 \%$ se debe a que la diferencia está dada por ausencia de respuesta o respuestas neutras.

En relación a la integración social, predomina la integración satisfactoria, $72,6 \%$ del total, la relación insatisfactoria se da en el $26,1 \%$, correspondiendo el $15,2 \%$ a los varones y el $36,7 \%$ a las mujeres, diferencia que resultó estadísticamente significativa.

\section{Vision de Mundo}

En relación a visión de mundo, predomina en el grupo la visión realista $39,2 \%$; la visión idealista se obtiene en el $30 \%$ y la visión negativa en un $25,5 \%$ de los casos. En un $5,5 \%$ no es posible precisarla.

En el grupo total predominan las visiones de mundo realistas, $39,2 \%$, e idealistas $30 \%$, dándose las visiones negativas en un $25,5 \%$ de los casos.

Encontramos una relación estadísticamente significativa entre las diferentes visiones y la expresión emocional, y también con algunas conductas socialmente desadaptivas como la embriaguez, el consumo de drogas y el hurto. En relación a la expresión emocional, encontramos que los jóvenes jdealistas expresan en forma más satisfactoria todas las emociones especialmente el afecto; los realistas expresan también preponderantemente en forma satisfactoria, pero en menos proporción que los idealistas; los jóvenes con posiciones negativas expresan en forma insatisfactoria las emociones especialmente el temor, la tristeza y el afecto.

La embriaguez, el consumo de drogas y los hurtos, se dieron en jóvenes de ambos sexos, con visiones realistas y especialmente en los con posiciones negativas, no presentándose estas conductas en jóvenes con posiciones idealistas.

También encontramos una relación significativa entre la visión de mundo $\mathrm{y}$ las aspiraciones vocacionales. Los jóvenes con posiciones idealistas tienen aspiraciones vocacionales más altas que los realistas, ya que aspiran sólo a profesiones universitarias o técnicas, en cambio los realistas también eligen ocupaciones de menos prestigio, como la de empleados y obreros.

En nuestro grupo encontramos que la mayoría de los jóvenes $(65,8 \%)$ presentan relaciones interpersonales satisfactorias en todas las áreas, sin encontrarse diferencias estadisticamente signifjcativas por sexo. Las relaciones interpersonales insatisfactorias se dan en un $\mathbf{3 4 , 2 \%}$ de los jóve. nes, distribuyéndose principalmente en el área familiar $(26 \%)$, en menor porcentaje en el área escolar (16\%) y en todas las áreas en sólo $8,4 \%$. La suma de porcentajes parciales en las relaciones insatisfactorias supera el total porque existe superposición de áreas.

Al relacionar la visión de mundo con las relaciones interpersonales encontramos correlaciones estadísticamente significativas. Los jóvenes con visiones idealistas son los que tienen en mayor proporción $(82 \%)$ relaciones interpersonales satisfactorias en todas las áreas, seguidos por los realistas. Los jóvenes con visión de mundo negativas presentan en su mayoría problemas relacionales en las áreas familiar o escolar.

En relación a conductas socialmente desajustadas, como consumo de drogas, embriaguez y hurtos, se observa que éstas se dan preferentemente en jóvenes que presentan problemas en las relaciones interpersonales, especialmente en el àrea familiar y también en la escolar. 


\section{COMENTARIOS}

Mediante el análisis psicosocial realizado intentamos identificar factores de riesgo para la salud mental del adolescente, los que pueden encontrarse ya sea en la persona, en el medio ambiente o en ambos, en una interacción permanente. De acuerdó a los datos obtenidos en este estudio estos factores podemos identificarlos en la visión de mundo, relaciones interpersonales $o$ en la presentación de conductas socialmente desadaptativas.

En el área personal encontramos que las dificultades de ajuste se relacionan con la autoimagen negativa, las visiones de mundo negativas, la expresión emocional insatisfactoria y los trastornos conductuales.

En relación a la imagen negativa de sí mismo se ha planteado que ésta se expresa en escasa participación social, conductas desadaptativas, tendencias al aislamiento y excesiva dependencia de las ideas de otros, mayor frecuencia de problemas de rendimiento y de relaciones interpersonales insatisfactorias. Las personas que solicitan ayuda psicológica y psiquiátrica reconocen frecuentemente que se perciben a si mismos en forma negativa; como inútiles, inferiores, incapaces de dar o recibir afecto, menosprecian sus potencialidades y realizaciones, tendiendo generalmente a la depresión, ansiedad y culpa, lo cual perturba su ajuste social y escolar ${ }^{7}$.

Consideramos que la egosintonía respecto a la imagen negativa de sí mismo, es un indicador de perturbaciones de la personalidad, ya que es patológico simpatizar con rasgos negativos. En cambio la egodistonja frente a una imagen negativa indica rechazo de ésta, lo que abre posibilidades de cambio y de ajuste. En los casos de imágenes positivas, la egodistonía indica problemas intrapersonales, ya que no es sano rechazar una imagen positiva de sí mismo, en tanto que la egosintonía respecto a imágenes positivas o de predominio positivas es un indicador de un desarrollo psicosocial normal para esta etapa etaria, ya que estos jóvenes son los que tienen la mejor adaptación personal y social, (Resultados área personal).

Es decir lo más deseable en esta fase, en cuanto a imagen personal, es una imagen positiva o de predominio positiva que se acepta como propia.

La expresión de emociones es necesaria para e] desarrollo personal y social. La alegría y el afecto favorecen la vida familiar y social ya que mantienen y enriquecen la calidad de las interacciones. Por otra parte, la expresión adecuada de la tristeza, el temor y la rabia favorecen un desarrollo personal equilibrado. En cambio la no expre- sión produce un estado de tensión emocional que afectará las relaciones interpersonales y que eventualmente llevará a expresiones exageradas e intensas de estas emociones provocando rechazo social. En este estudio la expresión emocional insatisfactoria predominaba en jóvenes con desajuste social. La expresión emocional depende en parte importante de patrones socio-culturales. Por los resultados obtenidos concluímos que en nuestra cultura se acepta mejor la expresjón de emociones positivas (alegria y afecto) que la expresión de las negativas (tristeza, temor y rabia). Postulamos que para el desarrollo psicológico satisfactorio lo deseable sería la expresión de todas las emociones en forma adecuada a la etapa etaria y contexto socio cultural. Pudimos observar que la expresión emocional insatisfactorja predominaba en jóvenes con desajustes sociales.

La vision de mundo, se relacionaría con la calidad del ajuste personal y social. La visión idealista resulta la más satisfactoria en esta etapa porque ésta se asocia a los mejores ajustes en todas las áreas. La visión realista resultó asociada a un ajuste menos satisfactorio que la anterior. Este resultado corrige el posible prejuicio de pensar que la imagen realista debería corresponder a lo de mejor ajuste. La visión negativa se asocia a problemas de ajuste personal y social. Consideramos que el adolescente debería lograr, al analizar el periodo, un equilibrio entre la visión idealista y la realista, lo cual implica haber encontrado por un lado la integridad personal y por otro el ajuste social.

Las relaciones interpersonales, sobre todo las familiares son indicador de riesgo en el desarrollo personal y social del joven. Los resultados indican que la familia en tanto imagen y relaciones interpersonales es ef factor anjoiertat más importante.

En la medida en que haya más áreas en que las relaciones interpersonales sean satisfactorias, mejor será el desarrollo psíquico del joven y mejor su adaptación al medio, no apareciendo generalmente conductas desajustadas. Por el contrario, cuando las relaciones están perturbadas en varias áteas, el ajuste psicológico es menor y se presen$\tan$ con mayor frecuencia conductas socialmente desadaptativas.

Diversas investigaciones han demostrado que la severidad de los conflictos del adolescente en relación a la dependencia-independencia, y la facilidad con que se resuelven hacia una mayor independencia, dependetá en gran medida de las relaciones familiares. También se ha visto que en casos en que hay conflictos entre valores dados por los padres y el grupo, la influencia relativa de ambos dependerá de la relación previa con los padres, ya que la adopción de los valores de los 
padres y el desartollo de la moral autónoma dependen en gran medida de la relación con éstos ${ }^{7}$. Cuando la familia cumple las funciones de dar apoyo, protección y seguridad a sus miembros, el desarrollo personal y social de los jovenes será más adecuado. Hemos observado en nuestra experiencia clínica que una familia desorganizada $y$ de interacciones hostiles habituales, facilita que el adolescente se evada en el alcohol o las drogas, y otras conductas socialmente desajustadas.

Cabe destacar en los aspectos familiares, que los jóvenes visualizan las relaciones con la madre como las más satisfactorias, lo que podría explicarse por el ejercicio del rol matemo en nuestra cultura, ya que la madre es la que realiza más definidamente las tareas educativas, estimulando el desarrollo de autonomía, entregando afecto, seguridad y confianza; en tanto que el padre aparece como más periférico, con menor compromiso en el ejercicio de su rol, generando asi relaciones escasas, distantes o de menor confianza.

Las instituciones educacionales aparecen junto con la familia, como los factores ambientales más importantes en relación a la entrega de protección y seguridad. La escuela influye especialmente a través del aprendizaje de valores, normas y roles sociales. En relaciones interpersonales, los profesores como figuras de autoridad, proporcionan modelos y figuras de identificación alternativas a las figuras parentales y la relación con los pares les facilita el control de la conducta social, la adquisición de destrezas e intereses propios de la edad, y también el compartir problemas y sentimientos comunes.

La alta proporción de relaciones insatisfactorias con los companeros podrían explicarse por la competitividad del escolar, y por la necesidad de la comparación con el grupo de pares para afjanzar el concepto de si mismo y la autoestima, lo que lleva a una actitud más crítica y a una apreciación más realista del otro. En una investigación anterior ${ }^{8}$, comprobamos que la escuela protege al joven de desarrollar conductas negativas, tales como abuso de drogas y alcohol, las que se dan en porcentajes menores en jóvenes que asisten a la escuela, en comparación a tos jóvenes que están desinsertados del sistema educacional.

En el área social, la imagen de otras personas en general e imágenes de personas del mismo sexo y del sexo opuesto, revelan en parte actitudes esterotipadas o prejuicios culturales en relación a los roles de ambos sexos, como también reflejan las experiencias de la persona misma, e influyen en forma importante las relaciones inter. personales y la visión de mundo del joven. Pudimos observar que la adolescente femenina tiene una imagen del matrimonio más realista y menos idealizada que el varón, ya que en nuestra cultura la mujer de nivel medio y bajo (representado en nuestra muestra), tendría más responsabilidad y menor libertad en el matrimonio, dándose problemas de autonomía y realización personal. El hecho de que hayamos encontrado que la mujer tiene una integración social más insatistactoria que el hombre, recalca las diferencias de tipo sociocultural, ya que a la mujer se le otorgarían menos libertades, no facilitando tanto como en el hombre la independencia e integración a nivel social. La mujer integra menos a grupos de pares y tiende a permanecer más ligada al grupo familiar, lo que coarta sus interacciones en el ámbito social.

La consideración de estos factores psicosociales tanto personales como ambientales nos permite diferenciar entre el adolescente normal, el adolescente normal en riesgo y el adolescente con patología. El adolescente normal sin riesgo, es aquel que presenta imágenes positivas de sí mismo, de las figuras parenterales y de las instituciones en general, predominando visiones de mundo idealista, con relaciones interpersonales satisfactorias y sin la presencia de conductas socialmente desajustadas. El adolescente en riesgo sería aquel que puede presentar ciertos desajustes personales y sociales, como experiencias únicas, teniendo una visión personal y de mundo realista o negativa y ciertas dificultades de relación interpersonal. El adolescente con patología psicosocial sería aquel que presenta habitualmente conductas desajustadas, y cuya visión del mundo es predominantemente negativa, y sus relaciones interpersonales son escasaz o insatisfactorias en distintas áreas.

Consideramos que el cuestionario utilizado en este estudio permite conocer algunos aspectos de la salud mental del adolescente, pudiendo identificar en forma expedita y masiva a los adolescentes en riesgo en cuanto a salud mental, lo que es importante especialmente en este grupo etario que carece habitualmente de un control médjco periódico. Esta identificación temprana, pernitirá elaborar medidas preventivas a nivel de educación y salud y realizar intervenciones terapéuticas oportunas y precoces en casos de riesgo o de patología.

\section{RESUMEN}

Se describen algunas características del desarrollo psicosocial en un grupo de 383 adolescentes de ambos sexos, de 12,6 a 15 años de edad, que pertenecen a un estudio longitudinal de crecimiento y desarrollo que se extiende desde los 5 hasta los 20 años de edad.

Se aualizan aspectos del desarrollo personal y 
de las relaciones interpersonales, en las áreas familiar, escolar y social. Los aspectos conductuales fueron motivo de una publicación anterior.

Se identifican factores de riesgo para la salud mental, lo que nos permitirían diferenciar entre el adolescente normal, el adolescente normal en riesgo, y el adolescente con patología neuropsiquiátrica.

Los factores de riesgo desde lo personal, serían tanto la autoimagen, como las visiones de mundo negativas, la expresión emocional insatisfactoria y conductas socialmente desajustadas, como el abuso de alcohol, drogas y hurtos. Desde el ambiente los factores de riesgo más relevantes, serian las relaciones interpersonales insatisfactorias, especialmente en el área familiar.

\section{REFERENCIAS}

1. Avendaño, A., Avendaho, P., Atmonte C., Sepúlye. $d a, G$., Valenzuela $C$.: Características del desarrollo psicosocial en adolescentes de 12 a 15 años. Sontiago Norte. Rev. Chil. Pediatr. 54: 273, 1983.

2. Steinhauer, $P$.: Infancy and Chilhood. Greben, S. y otros. Lea y Febiger, Philadelphia, 1980.

3. Kaempffer, A.M.: Mortalidad y Morbilidad del adolescente en Chile. Peditr. (Santiago) 20: 17, 1977.

4. Rosselot $J$ : Problemática de la salud đel adolescente y del joven en Latinoamérica y el Caribe. Pediatría. (Santiago) 20; 7, 1977 .

5. Zinn, D.: A developmental preventive approach to problems of Psychotology in adolescence. En Basic Handbook of Child Psychiatry IV - Basic Books, N. York, 1979.

6. Avendafio, A., Valenzuela. C. y colaboradores: Estudio longitudinal de crecimiento y desarrollo de un $10 \%$ đe los niños que ingtesan a la Enseñanza Básica Fiscal. Area Hospitalaria Norte de Santiago. Pediatría (Santiago) 19: 156, 1976.

7. Mussen, P.H., Conger, J.J., Kagan, J.: Desarfallo de la personalidad en el niño. Editopjal Trillas, México, 1973.

8. Avendaño, A., Almonte, C. y coloboradores: Estudio de algunas características sobre la aplicación del Test de Willougby y descripción de conductas de grupos de adolescentes. Pediatría (Santiago)20: 255, 1977. 